\title{
Görkemli Bir İslam Mabedi: Abu Dabi, Şeyh Zayed Bin Sultan El Nayan Camii
}

\author{
S. Cengiz YESÜGEY *
}

\section{Giriş}

Şeyh Zayed bin Sultan El Nayan camii, Birleşik Arap emirliklerinin başkenti Abu Dabi'de, 1990-2004 yılları arasında inşa edilmiştir. 1988 yılında, mimar Doğan Kuban ve Cafer Bozkurt’un da üçüncülüğü kazandığı (Mimarizm, 2008) uluslararası bir tasarım yarışması sonucunda Suriyeli mimar Yousef Abdelky ${ }^{\top}$ tarafından tasarlanmıştır (Syriart, 2012). Değişik kaynaklar tarafından dünyanın en büyük camilerinden biri olarak kabul edilmektedir (en.wikipedia, 2012). Birleşik Arap Emirlikleri devlet başkanı Şeyh Zayed Bin Sultan El Nayan tarafından 1996 yılında başlatılan bu proje, 2004 yılında ölümünden sonra adını almıştır. Kendisi de bu kompleks içerisinde bir türbede yatmaktadır (Fotoğraf 1).

Proje 2007 yılında tamamlanıp halka açılmış olmasına rağmen, dış çevre düzenlenmeleri ancak 2010 yılında tamamlanabilmiştir. Bu çalışmada amaç, başta Guiness rekorlar kitabıadaylığı olmaküzerebirçoködüle layıkgörülen bu eserin, mimari ve tezyinata ilişkin karakteristiklerini farklı kaynaklar ve kişisel gözlemler ile tanıtmaktır (Fotoğraf 2).

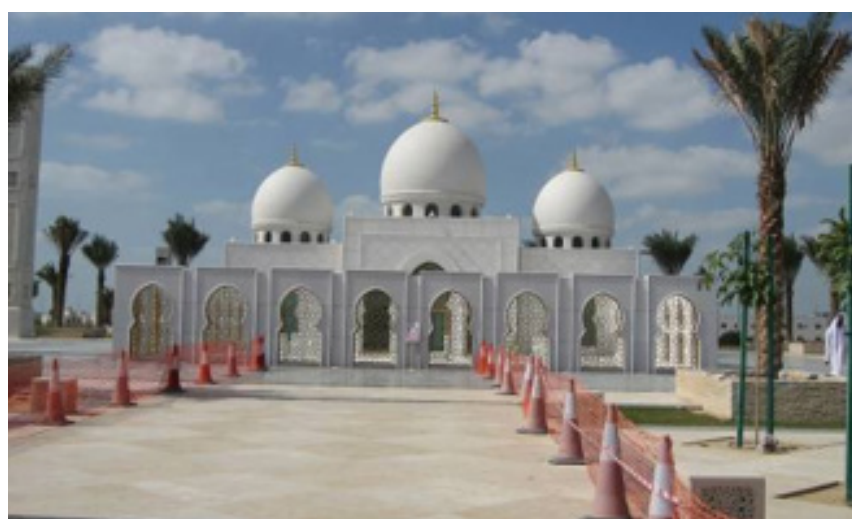

Fotoğraf 1. Şeyh Zayed Bin Sultan El Nayan Türbesi (Yesügey, 2009)

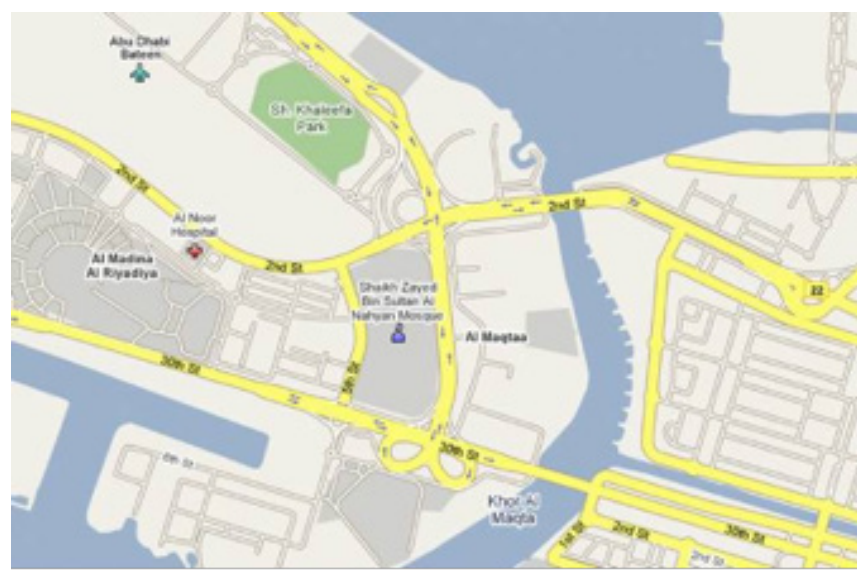

Fotoğraf 2. Caminin yeri (abudhabi.ae, 2012)

\section{Yapının Projelendirme ilkeleri ve Mimari ve Teyzinata} ilişkin Tanıtımı

Projenin çıkış noktası; Mimar Doğan Kuban'ın yorumu ile "tüm İslam aleminde değişik form ve tezyinat kavramları ile ifade edilen değişik İslami üslupların tek bir eserde uyumlu bir şekilde ele alınması olarak" nitelenebilir (mimarizm, 2008). Nitekim, proje incelendiğinde, başta Türk ve Arap camii mimarisi olmak üzere, Kuzey Afrika, İran, Hindistan vb. ülkelerdeki İslam mimari çizgileri ve motiflerinin bir uyum halinde tasarıma uygulandığı göze çarpmaktadır. Örneğin, varaklı avlu ve dört köşede yer alan kitleler Osmanlı, varaklı avlunun yuvarlak kemerleri Kuzey Afrika, Emevi ve Kordoba, kademeli minareler Mağribi ve Mısır Memluk, kubbe formları ise Arap üslubunu çağrıştırmaktadır (eogrenme.anadolu, 2012) (Fotoğraf 3). Bu da, tüm İslam eserlerine saygıyı sentezleyen abidevi bir yapıyı ortaya koymuştur. 


\section{Mimari Ölçüler}

Cami genel görünüm açısından deniz seviyesine göre 9.5 m. yüksekliğinde bir tepede inşa edilmiş olup, toplam alanı 22412 m2'dir. i̇ç ve dış mekânda toplam 40960 kişi ibadet edebilmektedir (szgmc.ae, 2012).

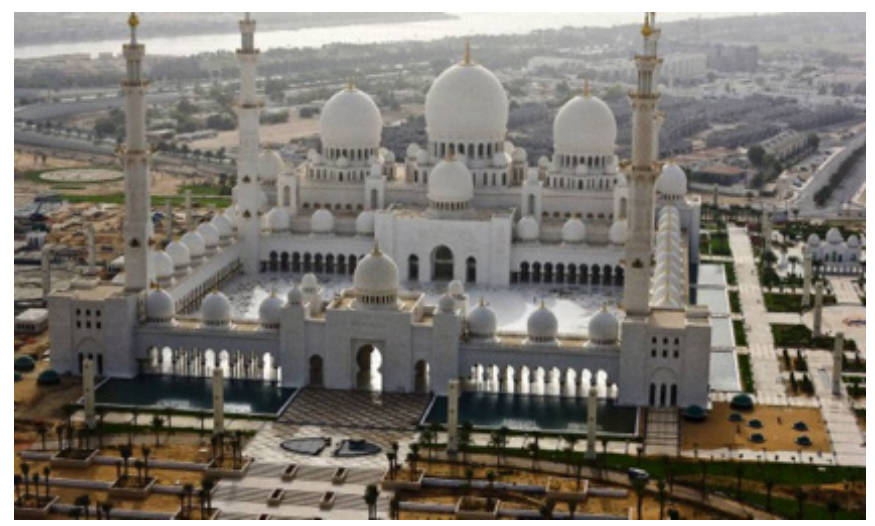

Fotoğraf 3. Havadan görünüş (randomphotography, 2012).

Kapalı orta mekân, 6000 erkek, her iki tarafta yer alan ve her biri 1500 kişi kapasiteli iki bölüm de kadınlar için olmak üzere 9000 kişinin ibadetine olanak vermektedir. İç ve dış mekân, üstleri irili ufaklı 82 adet Arap mimari kubbe formu ile örtülmüştür. İç mekânı örten üç büyük kubbeden merkezdekinin çapı 32.80 m. olup, kubbe yüksekliği içeriden 70.0 m., dışarıdan 87.0 m.dir. Yapı, iç mekânda 96, dış mekânda 1048 adet kolon tarafından taşınmaktadır. Kompleksin dört köşesinde 107 m. yüksekliḡinde dört adet üç şerefeli minare bulunmaktadır (Fotoğraf 4). Yapı strüktürü betonarme kabuk ve betonarme karkas olarak inşa edilmiş ve yapımda 250,000 m3 beton ve 33,000 ton çelik kullanılmıştır (abudhabi.ae, 2012).

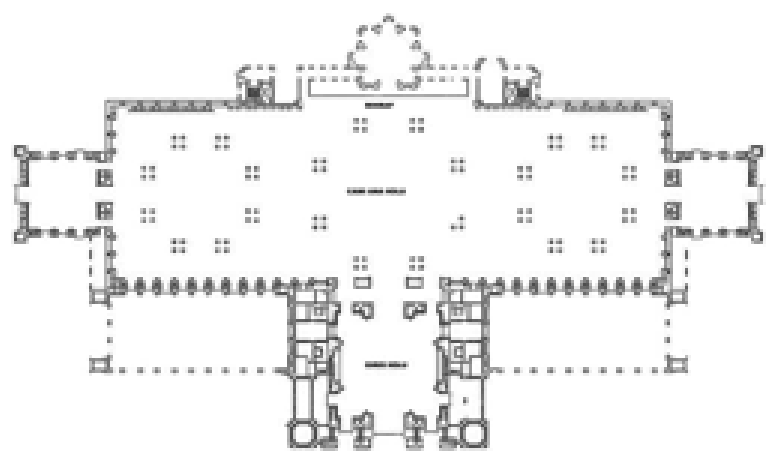

Fotoğraf 4. Ana yapı plan (archpresspk, 2012).

\section{Yapının Genel Mimari Özellikleri}

Yapıya üstü küçük kubbelerle oluşturulmuş, çifte kolonlarla taşınan kemerlerle oluşturulmuş çepeçevre revaklı süslü büyük bir ana avlu yoluyla kuzey yönünden girilmektedir. Bu avlu son cemaat bölümüne elveren 18,000 m2 büyüklüğünde olup yapı ana girişini vurgulamanın yanı sıra tüm yapının da görkemini ifade eden bir anlayışla tasarlanmıştır.

Avlu tamamiyle Makedonya Sivec mermeri ile kaplanmış olup (Makrana, 2012), (Fotoğraf 5-6), bu avlunun üç tarafını $7874 \mathrm{~m} 2$ alana sahip, beyaz mermer ve desenli mozaiklerle bezeli büyük revaklı geçit ve havuz çevrelemektedir (Fotoğraf 7-8). Revaklar çift kolonlu ve çift kolonlar arası yuvarlak kemerli olup, sütun başları altın yaldızlı hurma desenli olarak tasarlanmıştır. Kolon yüzeyleri

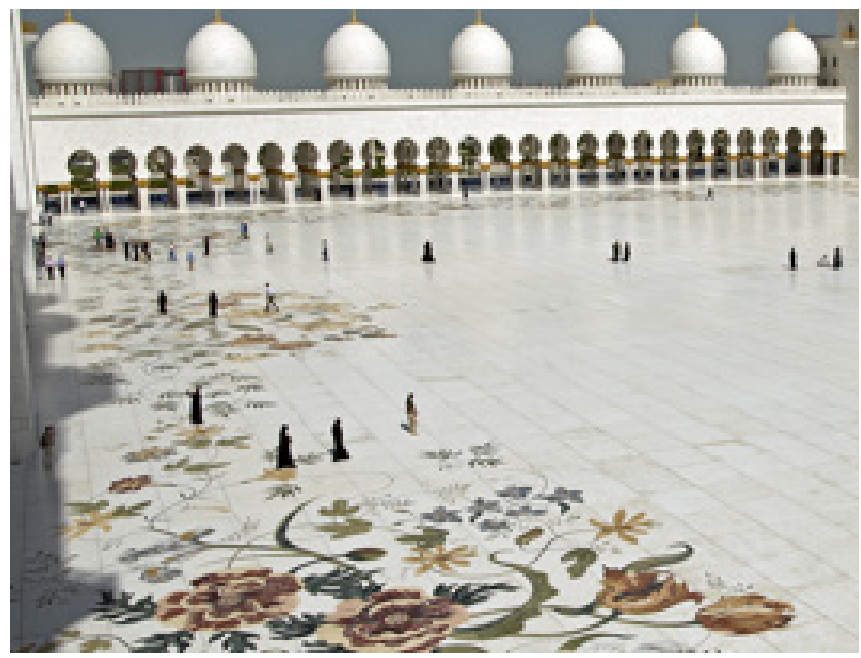

Fotoğraf 5. iç Avlu (Kevindean,2012).

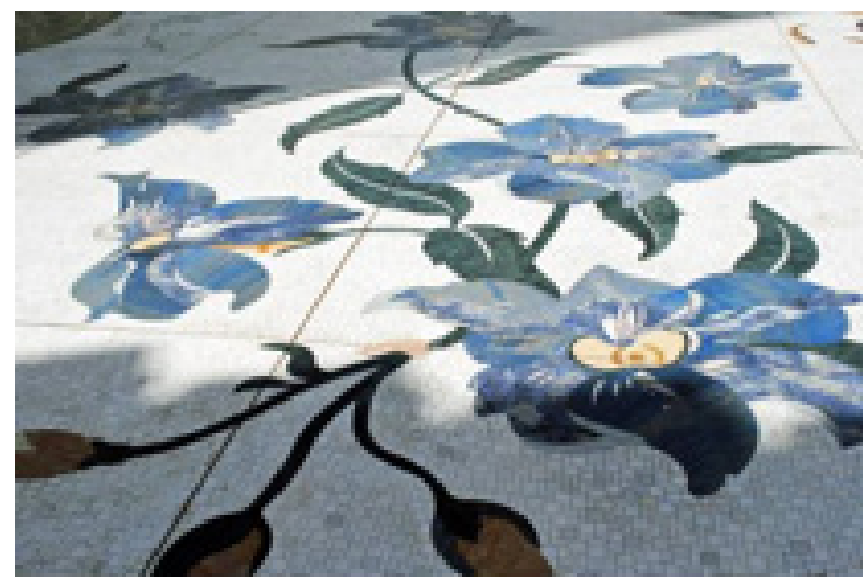

Fotoğraf 6. Çiçek Motifli Mermer Kaplama (thishandcraftedlife, 2012). 
ve zemin de aynen dış avlu gibi mermer üzerine el işi mozaik olarak işlenmiş ve Arap teyzinat sanatında çok kullanılan süsen, lale, lilyum ve gül çiçek desenleri ile bezenmiştir. (bigprojectme, 2013). Bu bezemeler İngiliz sanatçı Kevin Dean ${ }^{2}$ tarafından yapıımıştır (Kevindean, 2012) (Fotoğraf 5-6). Türk tezyinat sanatındaki Hatayi grubu altında toplanan yaprak, penç, goncagül ve yarı usluplandırılmış çiçekler grubunu andırsa da (eogrenme.anadolu, 2012) sanatçı bu resimlerin şimdiki Şeyh'in de onayı ile geleneksel ve geometrik İslam motiflerinin modern bir şekilde ifadesi olarak tasarlandığını ifade etmektedir (bigprojectme, 2013), (gulfnews, 2013).

Motiflerin oluşturulduğu mozaikler Italyan Fantini Mosaici tarafından su jeti tekniği ile kesilerek hazırlanan 37 ayrı renkte ve ebatta mermerlerin elle döşenmesi ile oluşturulmuştur. Avluda caminin görkemli görüntüsü algılanarak yapılan uzunca bir yürüyüşten sonra, üstü büyük

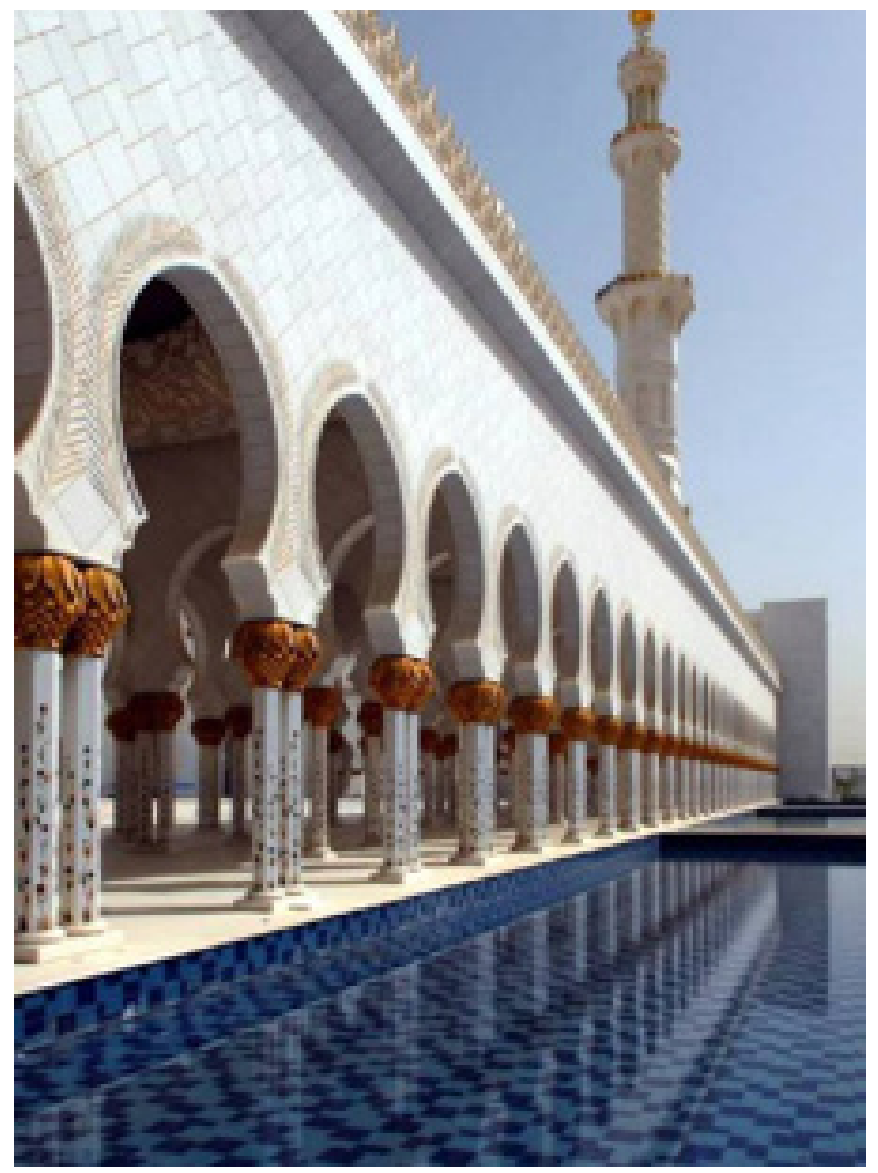

Fotoğraf 7. Revak ve havuz (wirednewyork, 2012)

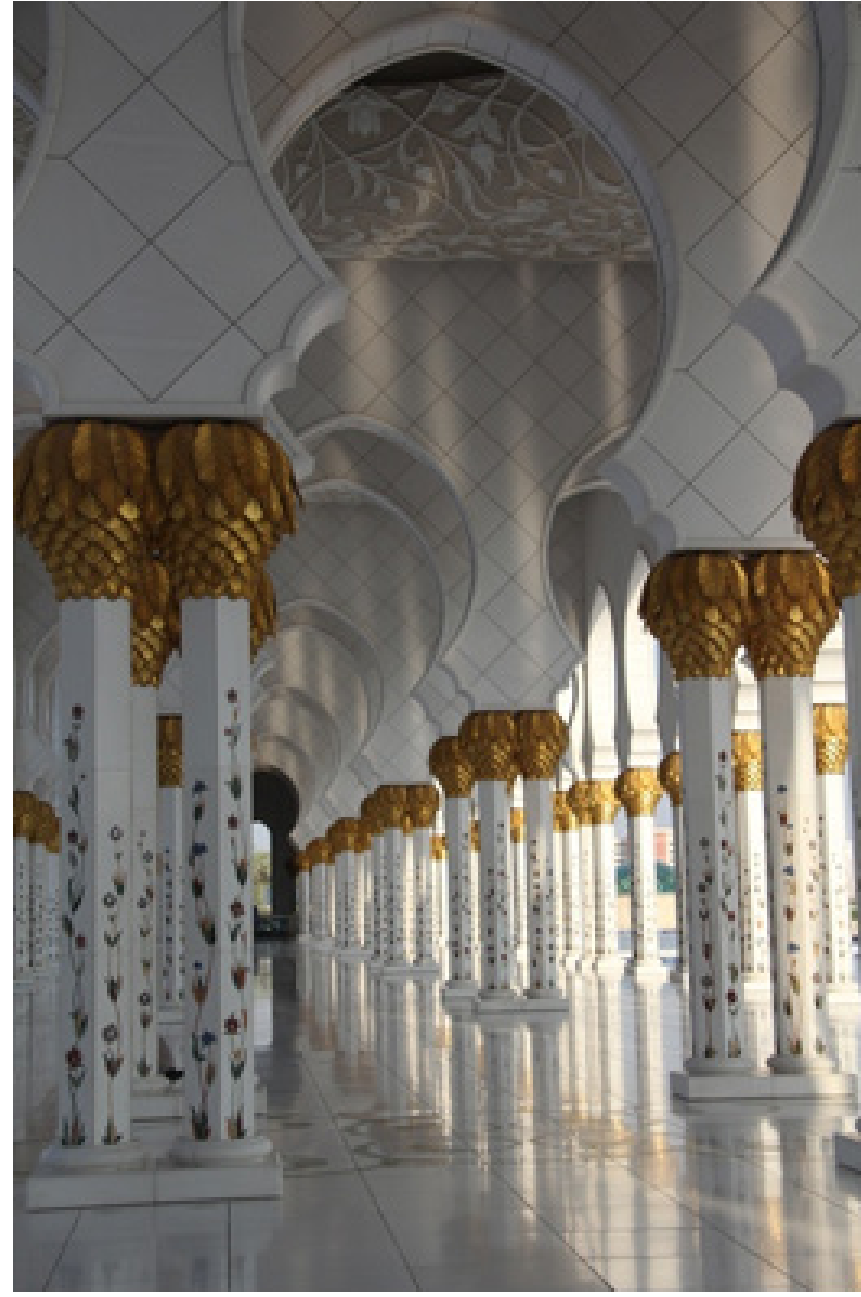

Fotoğraf 8. Revaklı geçit (nicolholden designes, 2012).

bir kubbeyle taçlandırılmış revaklı büyük bir giriş bölümüne ulaşılmaktadır. Zemini Italyan Lasa beyaz mermeri ile kaplı bu giriş mekânın zemini de Kevin Dean tarafından mozaik tekniği ile çiçek motifleri ile bezenmiş olup, duvarları yine aynı sanatçı tarafından mermer üzerine mermer kakma ve yapıştırma renkli çiçek deseni mozaiklerle bezenmiştir (Fotoğraf 9-11).

Bunun yanı sıra giriş bölümünün iç ve dış mekânlarındaki duvarlar yer yer değişik İslam kültürü tezyinatı bulunan çini panolarla süslenmiştir. Bunlardan 80 adedi el yapımı İznik çinileri ile süslenmiş panolardır. Bu panolar 'Iznik Vakıf Çinileri' adlı kuruluş tarafından (iznik.com, 2012) imal edilmiş olup, çok renkli (elvan) sır-altı tekniği (eogrenme. anadolu, 2012) ile üretilmiştir. 15. ve 16. yüzyıl Türk çini sanatı örneklerinden alınmış bu eserlerin bir kısmı ünlü ödüllü 


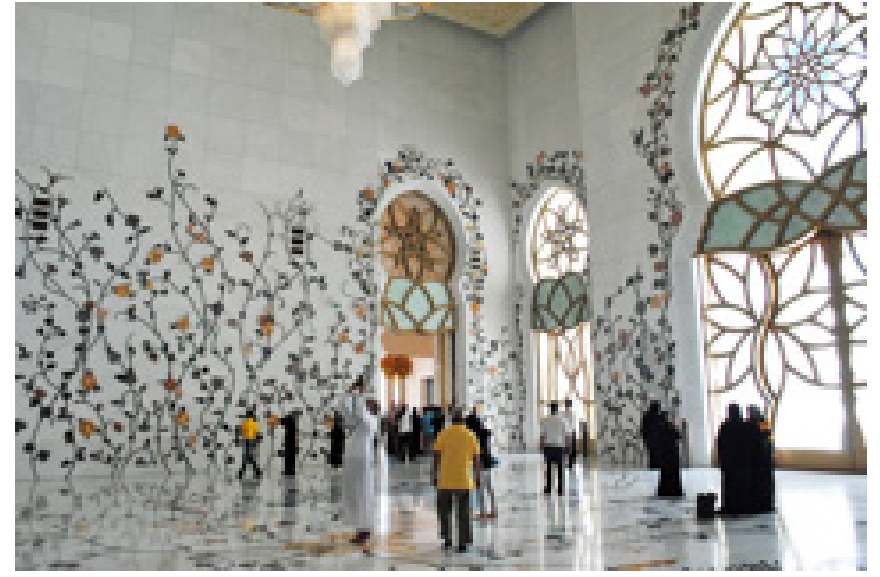

Fotoğraf 9. Ana Giriş (thishandcraftedlife, 2012)

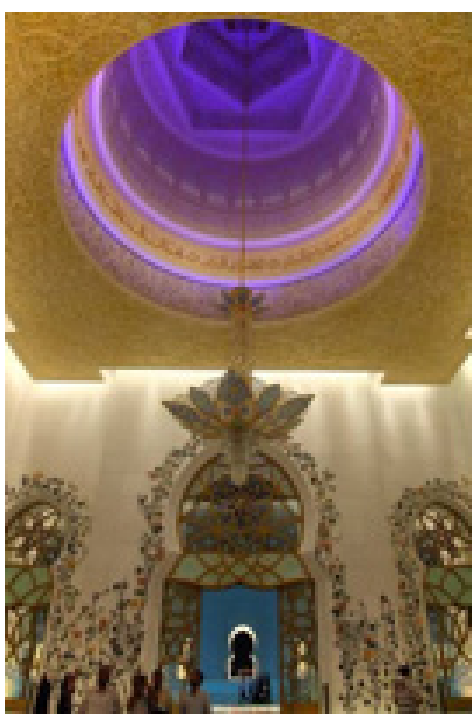

Fotoğraf 10. Ana Giriş ve Avizeli Salon (wirednewyork, 2012)

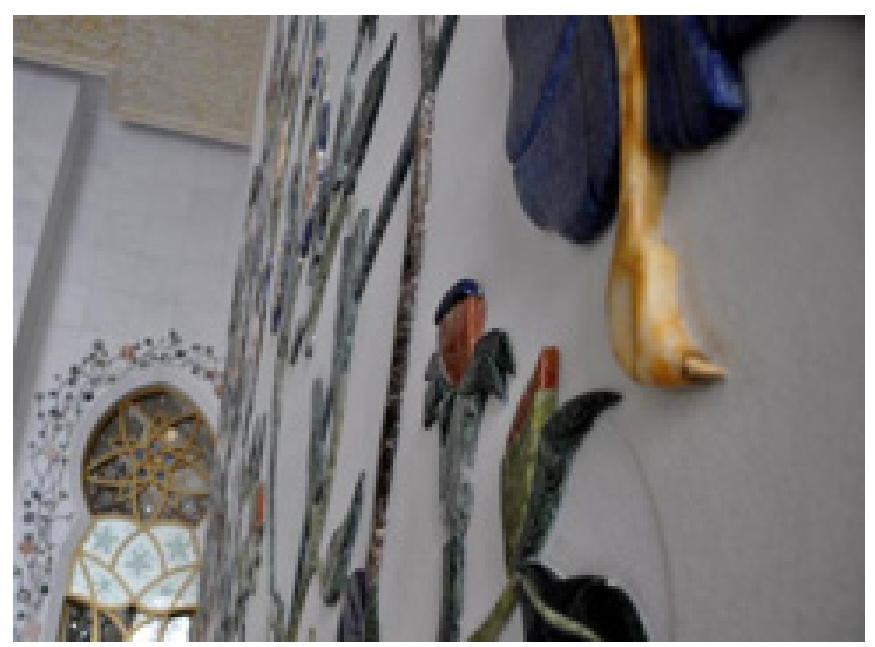

Fotoğraf 11. Duvar Süslemeleri (dubaiinmyeyes, 2012)

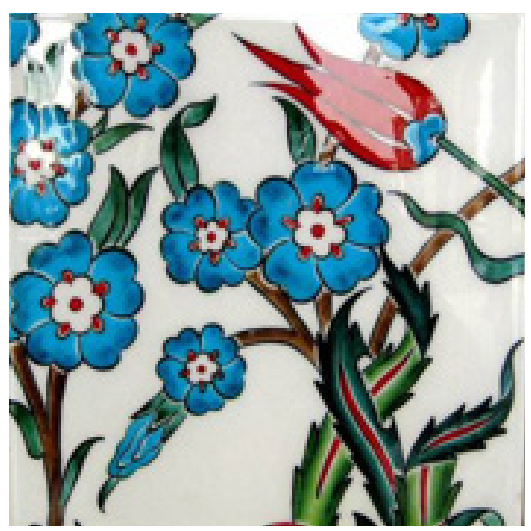

Fotoğraf 12. (Hewy, 2012)

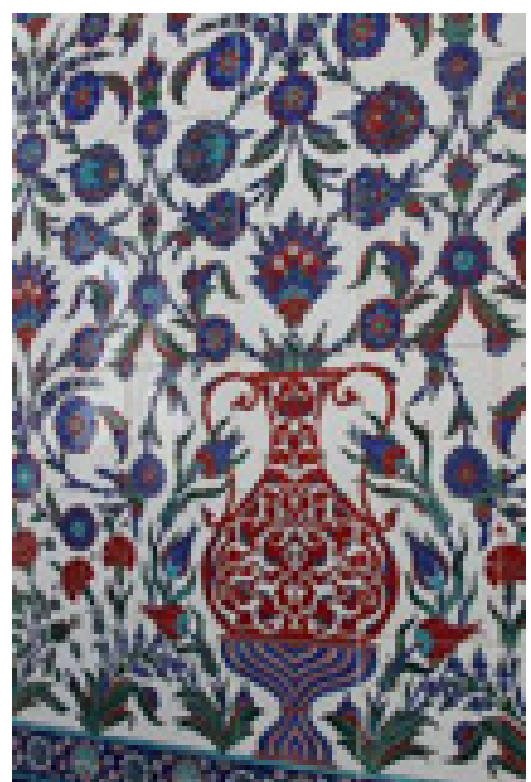

Fotoğraf 13. (mattwagers, 2008)

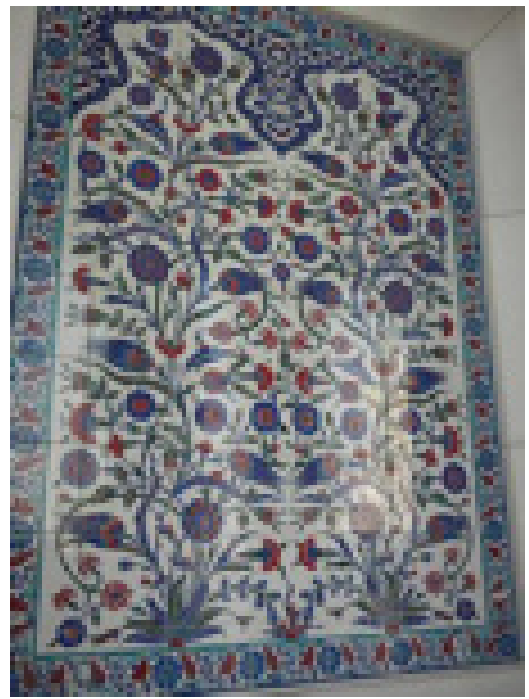

Fotoğraf 14. (@N04, 2011) 


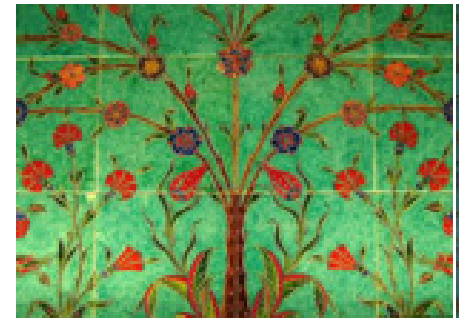

Fotoğraf 15. (jenny, 2008).

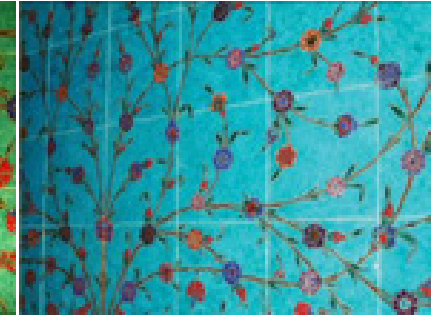

Fotoğraf 16. (iznik, 2012). hattat Hasan Çelebi ${ }^{3}$ tarafından tasarlanmıştır (kimkimdir, 2013), (tccb.gov, 2012) (Fotoğraf 12-16).

Caminin genelinde, "çiçek motifi" ağırlıklı bir kompozisyon bütünlüg̈ü ve Nakşi, Sulus ve Kufi tarzlarının (fanar.gov.qa, 2011) ağır bastığı bir yazı işçiliği göze çarpmaktadır. Tüm yapıda el yapımı ve ametist, istiridye kabuğu, inci lapis taşı, kırmızı akik gibi yarı değerli taşlarla kakma ve kaplama mermer panellerin 20000'i bulmaktadır (dubaifaqs, 2013). Tüm bu çalışmalarda Birleşik Arap Emirliklerinden Mohammed Mandi El Tamimi, Suriye'den Farouk Haddad ${ }^{4}$ (albarakaturk, 2008) ve Ürdün'den Mohammed Allam'ın katkıları bulunmaktadır. İç mekâna giriş devasa, camlı ve dekoratif süslemelerle bezenmiş kapılarla sağlanmaktadır (en.wikipedia, 2012).

Illk girişte tam karşıda yer almakta olan Mihrap, mermer üzerine 24 ayar altın kakma yivlerle süslenmiş bir bölüm olup, arka kısmı görevli imamların hazırlık mekânı olarak tasarlanmış ve tüm yapı göz önünde alındığında oldukça alçakgönüllü bir dekoratif görüntü arz etmektedir. Bunun hemen yanında olağanüstü incelikle oyma çiçek motifleri işlenmiş ahşap bir minber bulunmaktadır (Fotoğraf 17-18)

Ortada, doğu ve batı yönünde, dörder kolonlu altı ana düşey taşıyıcı ile taşınan üç büyük kubbenin oluşturduğu iç mekân, etkileyici bir toplu mekânı göz önüne sermektedir (Fotoğraf 19-21).

Kolonların üstü; deḡerli taşlar ve altınla süslü mermer üstü kakma motiflerle süslenmiştir. Tam karşıda ve Mihrap arkasında bulunan Kıble duvarıbeyaz mermer kolonlarınüstü; değerli taşlar ve altınla süslü mermer üstü kakma motiflerle süslenmiştir. Tam karşıda ve Mihrap arkasında bulunan Kıble duvarı da beyaz mermer kaplama üstü motiflerle süslü olup, 23 m. yüksekliğinde ve 53 m. genişliğindedir. Üzerinde Kufi 24 ayar altın harflerle "Allah"ın 99 ismi işlenmiş panolar halinde düzenlenmiş, panolar arası derzler arkadan fiber optik kablolarla aydınlatılmıştır (Fotoğraf 22-23). Yazılar ve motifler Birleşik Arap Emirliklerinden Mohammed Mandi El Tamimi ${ }^{5}$ (mandiarts, 2011) tarafından gerçekleştirilmiştir. Güney, batı ve kuzey duvarları renkli camlı vitraylı cam panolarla iç mekâna doğal ışığın girmesine elvermektedir.
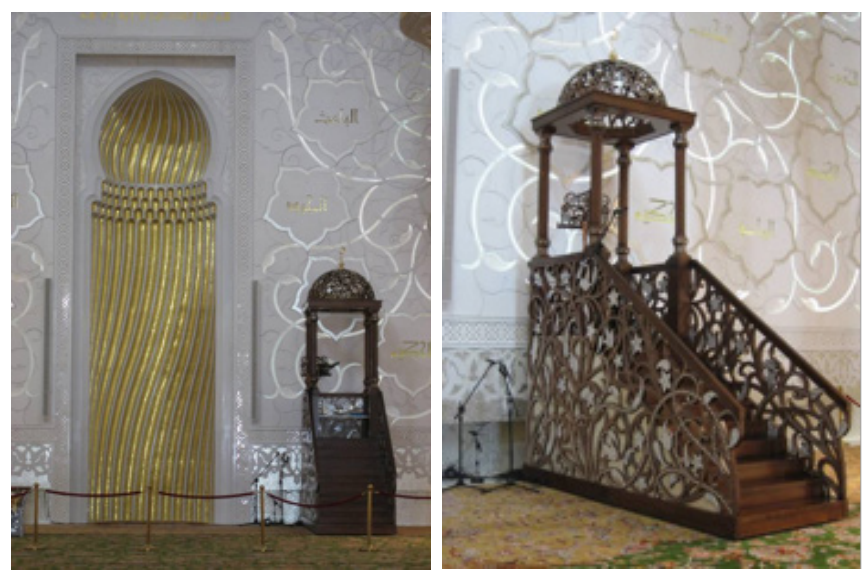

Fotoğraf 17.-18. Mihrap ve Minber (Yesügey, 2009)

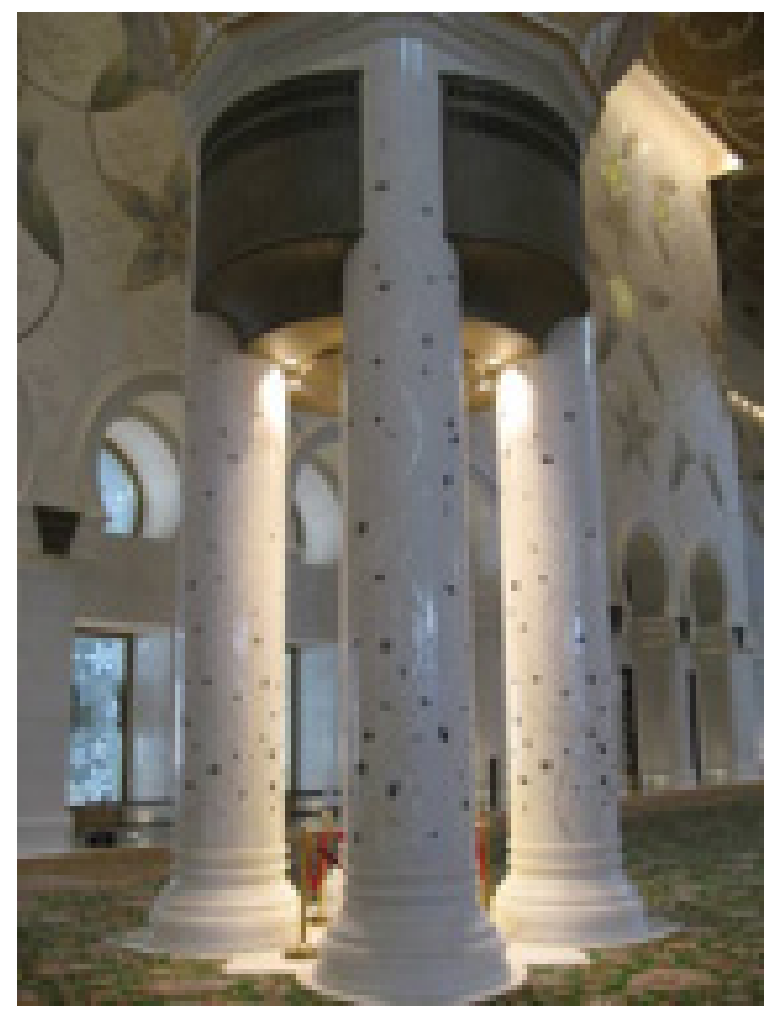

Fotoğraf 19. Dörderli taşıyıcı kolonlar (Yesügey, 2009). 


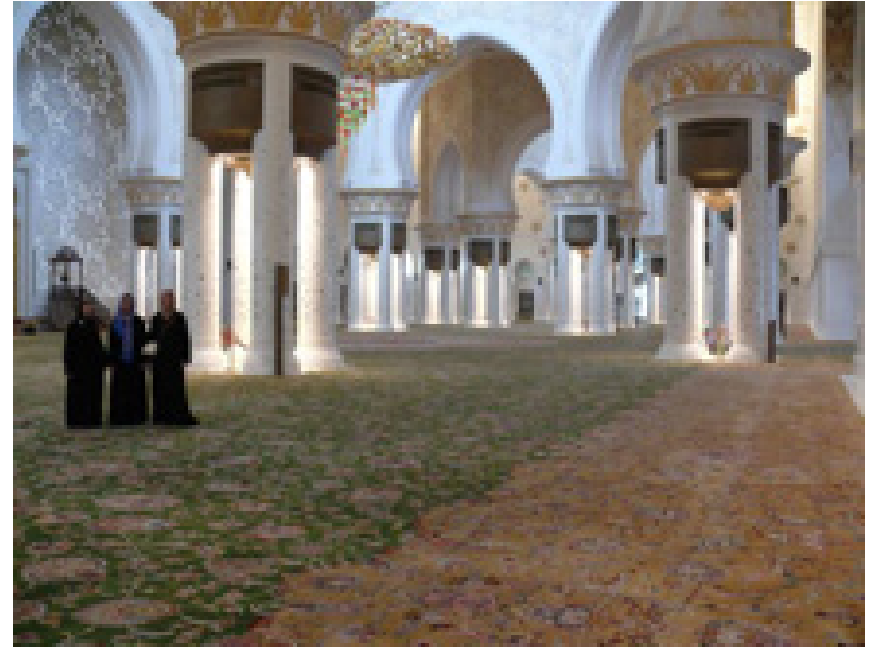

Fotoğraf 20 . iç mekân (Yesügey, 2009).

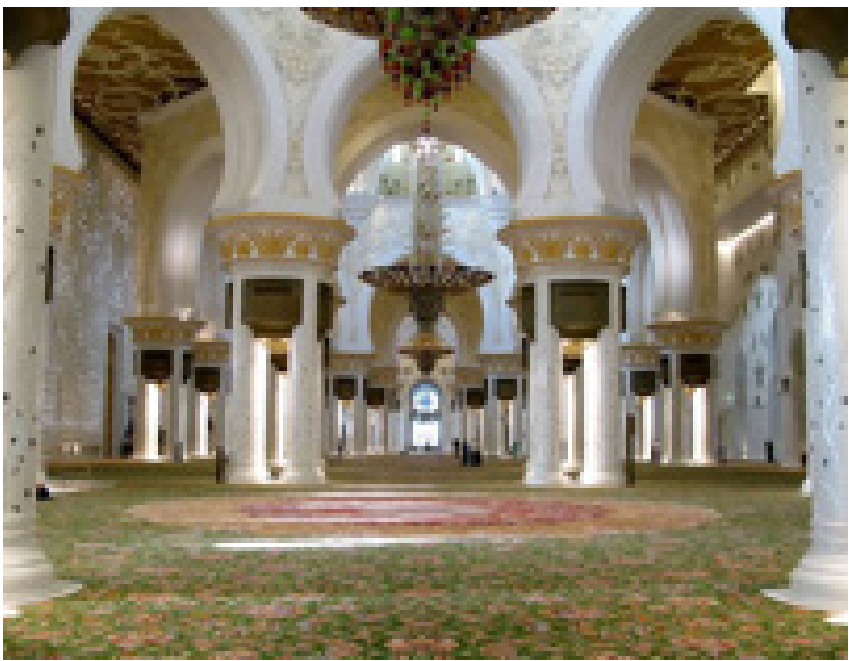

Fotoğraf 21. İç mekân (Yesügey, 2009).

Aynı zamanda bu duvarlar 24 ayar altın ve cam mozaik motiflerle bezenmiştir (Fotoğraf 24-25).

Zemin; olağanüstü desenlerle süslü, İran el yapımı ve Dr. Ali Khaliqi tarafından tasarlanmış, $7119 \mathrm{~m} 2$ büyüklüğünde, 2,268,000 ilmekle dokunmuş ve 45 ton ağırlığında dünyanın en büyük yekpare halısı ile kaplanmıştır (payvand, 2007) (Fotoğraf 26).

İç mekândaki her bir kubbenin ortasından her biri Alman yapımı, 24 ayar altınla kaplı, Swarovski kristali ile üretilmiş ve çok deḡerli taşlarla süslü üç büyük avize bulunmaktadır. Bu avizelerden orta mekânı süsleyeni dünyanın en büyük avizesi olup, çapı 10 m., yüksekliği 15 m. ve ağırlığı 9 ton'dur (Fotoğraf 27).

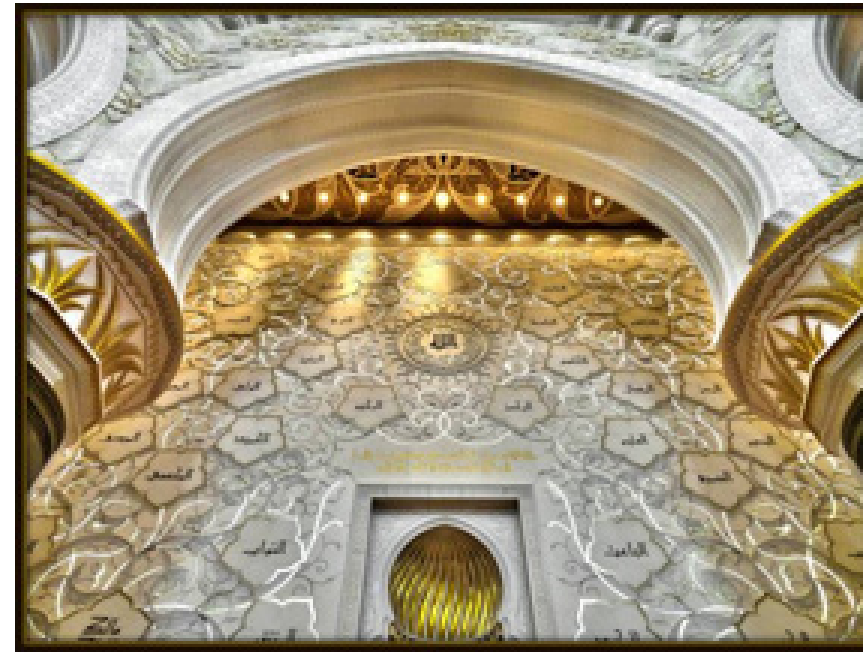

Fotoğraf 22. Kıble Duvarı (deviantart, 2013),

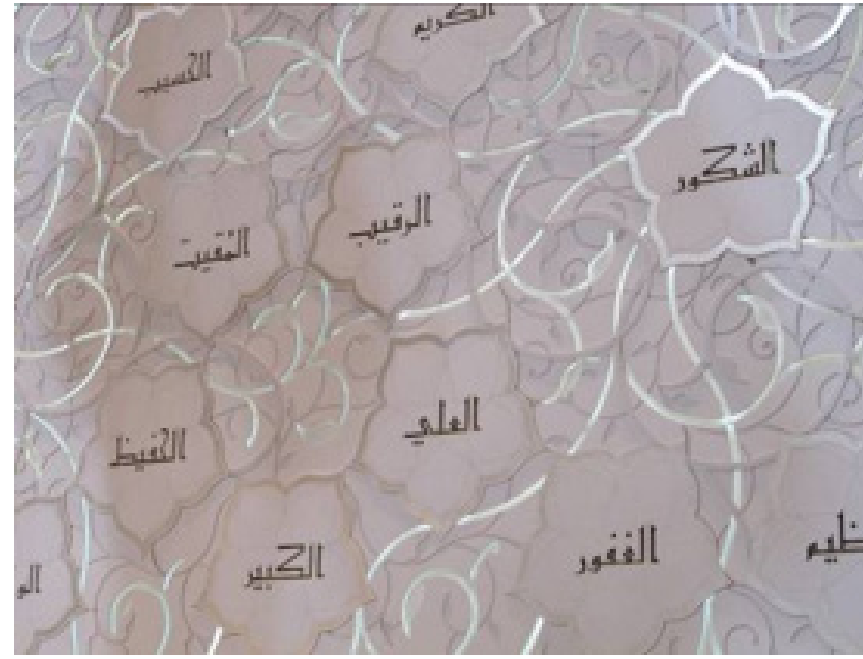

Fotograf 23. Duvar Yazı (amatraveller, 2011)

Yapı toplam maliyeti 545 milyon \$ olarak saptanmış olup, bu maliyet Guinees rekorlarına girmeye aday bir maliyettir. İç mekândaki her bir avizenin 8 milyon \$’a mal olduğu düşünüldüğünde bu bedeli yadsımamak gerekir (en. wikipedia, 2012).

Muhtelif yerlere konulmuş dev plazma ekranlarla verilen vaazların her yerden izlenmesi mümkündür. Yapıda aydınlatma ve iklimlendirme sistemi ustalıkla gizlenmiş ve tümüyle işlevsel olarak tasarlanmıştır. Örneḡin iç mekândaki büyük kolonların göze çarpmayan yüzeylerinde bile hava menfezleri bulunmaktadır. Aydınlatma iç ve dış mekânda, 3500 civarında ünite ile gerçekleştirilmiştir. Özellikle cami 


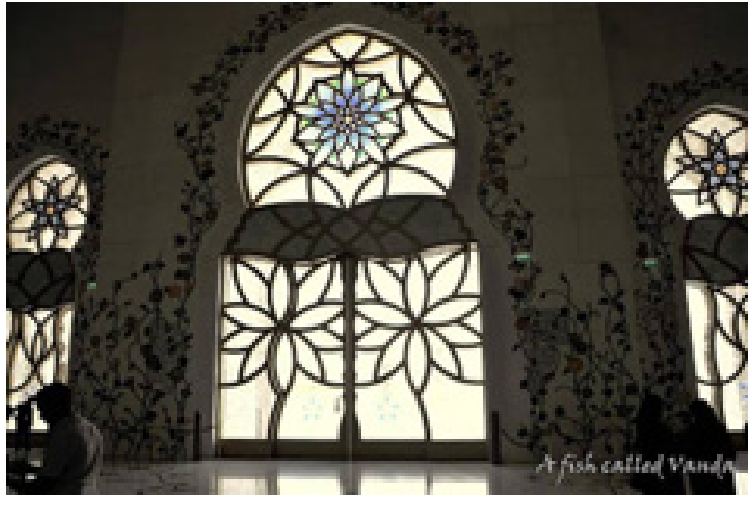

Fotoğraf 24. Vitraylar (dubaiinmyeyes, 2012).

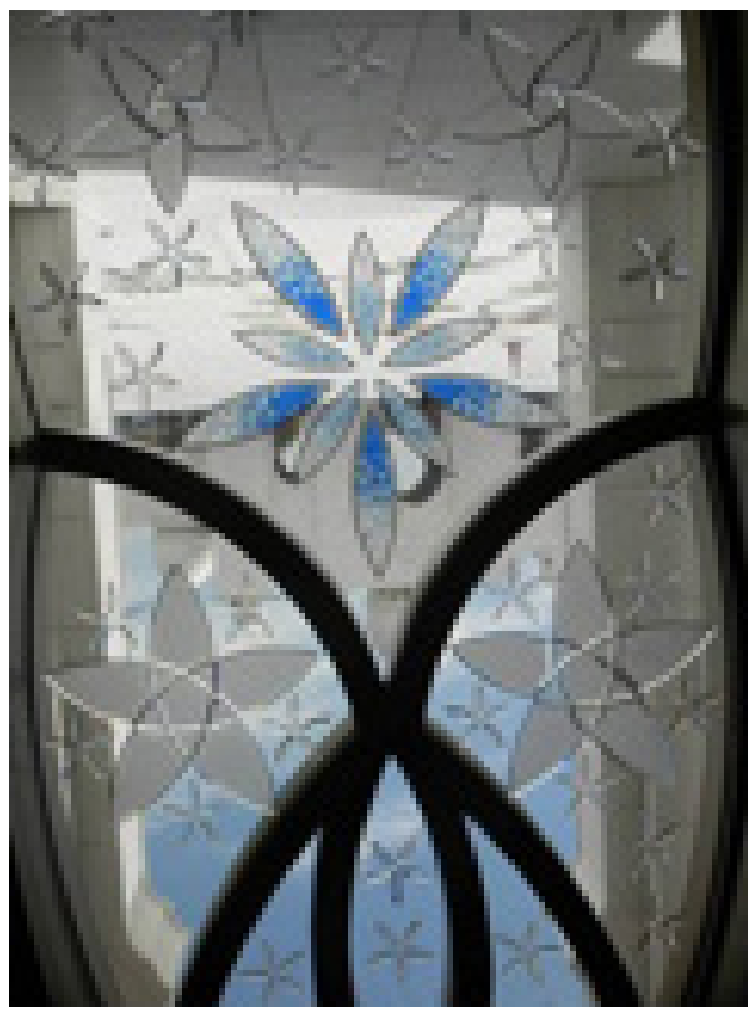

Fotoğraf 25.Vitraylar (amatraveller, 2011)

dış çevresinde bulunan aydınlatma kuleleri oldukça ilginçtir (Fotoğraf 28).

Aydınlatma projesi; Spiers and Major Associate firması tarafından hazırlanmış olup, 2010 yılında Yapı Aydınlatma Tasarımcıları Kuruluşunun (IALD) 26. Uluslararası aydınlatma tasarımı ödülünü kazanmıştır (speirsandmajor, 2012) (Fotoğraf 29).

\section{İnşasında Yer Alan Kuruluşlar}

Yapının proje ve ihalesi; Abu Dabi Devlet Bakanlığı tarafından

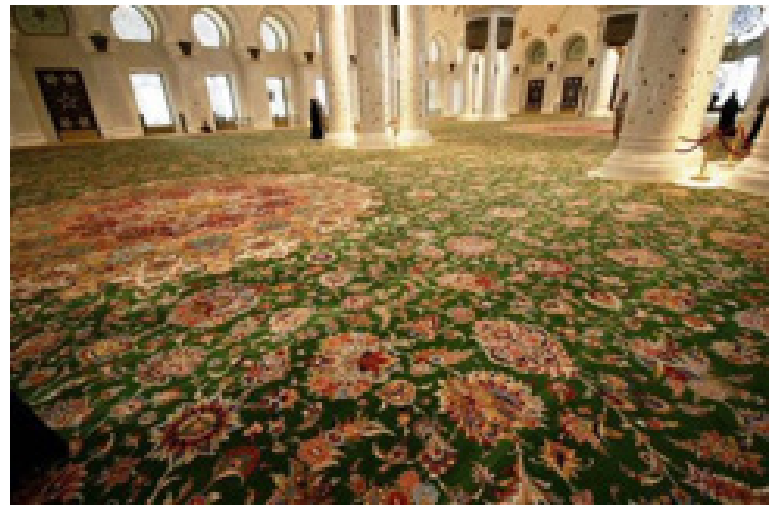

Fotoğraf 26. Halı (Yesügey, 2009)

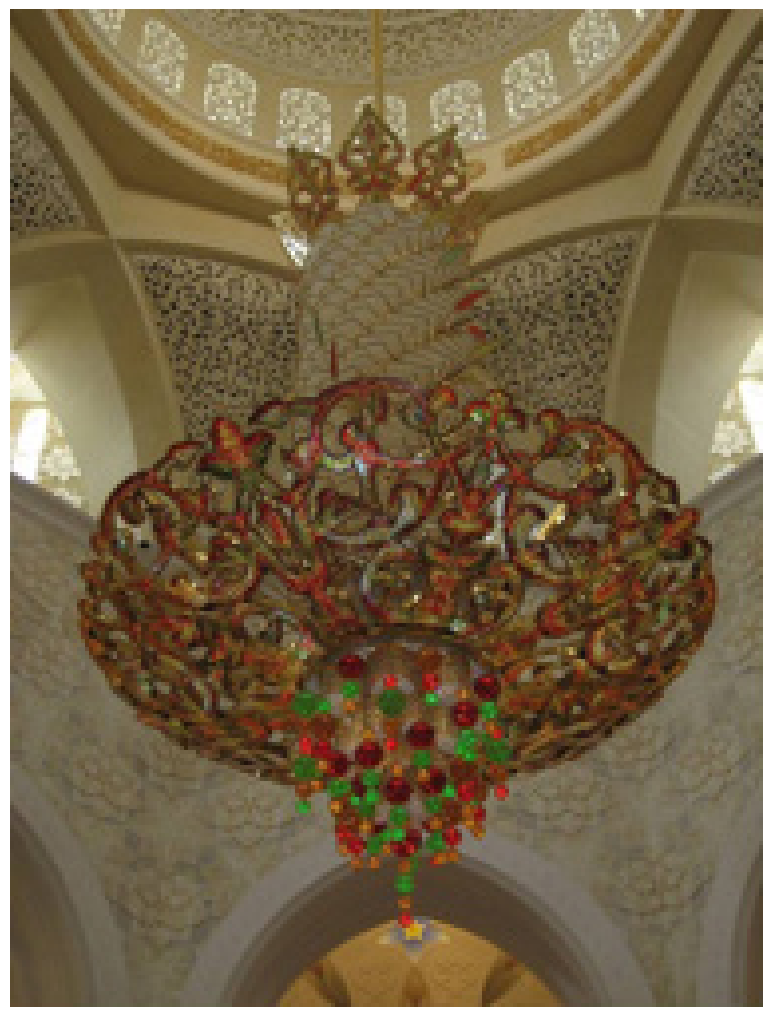

Fotoğraf 27. Büyük avize (Yesügey, 2009).

1990'ların sonunda başlatılmışır. Projenin yapımı değişik dönemlerde el değiştirmiş olmasına rağmen 2001 yııından itibaren Arap Yapım Şirketi olarak altı firmadan oluşan grup tarafından gerçekleştirilmiş olup (ACC); Proje ve yapım kontrolü Ingiliz Halcrow Group (http://www.halcrow. com), kalıp sistemleri uygulaması ise PERI kalıp firması (http://www.peri.de) tarafından yapılmıştır. Aydınlatma ödülü alan ve 2007 yılında bitirilen yapının, yazar tarafından ziyaret edilen 2009 yııında dış mekân düzenlemeleri halen devam etmekte idi. 


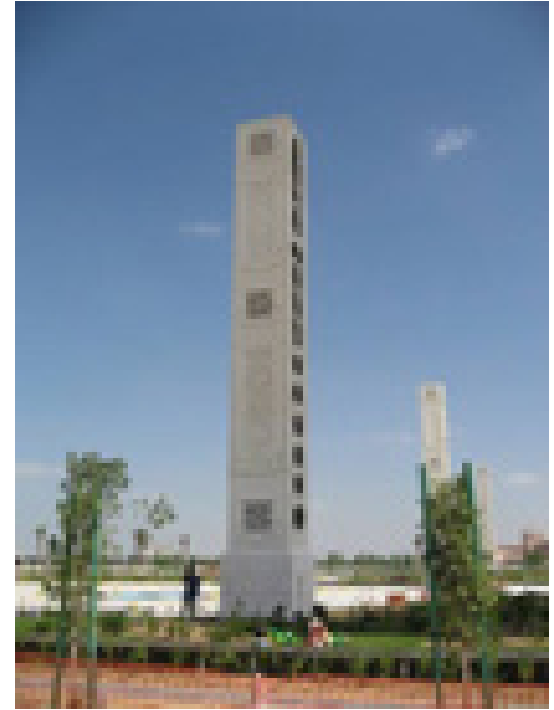

Fotoğraf 28. Dış mekân aydınlatma kuleleri (wirednewyork, 2012).

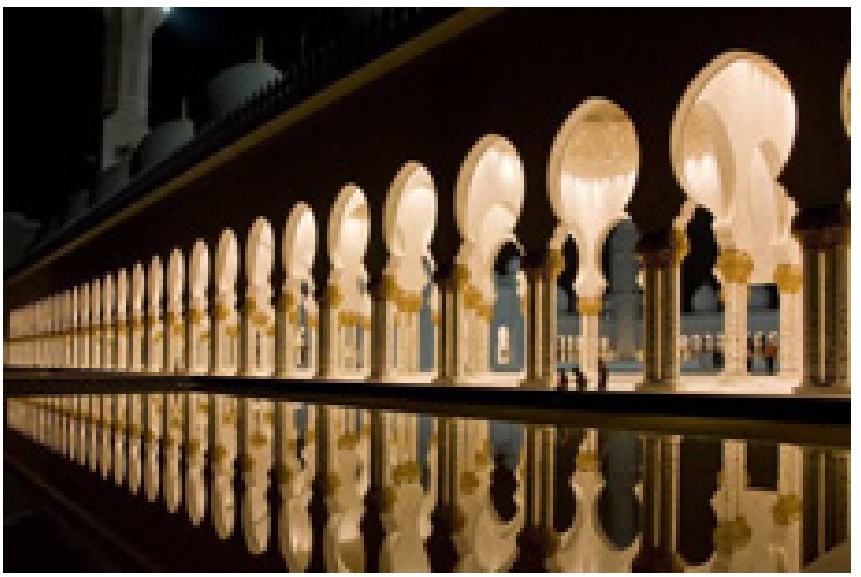

Fotoğraf 29. Aydınlatma (wirednewyork, 2012).

\section{Sonuç}

Başta da vurgulandığı gibi, bu araştırma, hiçbir şekilde tarihi süreçte inşa edilmiş birbirinden değerli eserlerle bir karşılaştırmayı amaçlamamaktadır. Ancak, gerek geleneksel Arap ve İslam mimarisi ve gerekse de değişik İslam sanat üsluplarına ilişkin tarihsel birikimin tek bir eserde ustaca sergilenebilmiş olması yapıya ayrı bir deḡer katmaktadır. Bunun yanı sıra, unutulmaya yüz tutmuş pek çok sanat türünün bu sayede dünya kamuoyuna sunulması, bu sanatların ileride de yaşatılması gayretlerine güzel bir örnek ve itici güç oluşturmaktadır.

\section{Notlar}

11951 yılında Suriye Quamechili de doğdu. 1976'da Şam Güzel Sanatlar Kolejinden mimar diploması aldı. 1986'da Paris National Superior School for Fine Art'da gravür sanatı üzerine çalıştı. 1989 yılında Paris Üniversitesinden Güzel Sanatlar Doktorası aldı.

2 Çok sayıda kitabı ve eserleri olan tanınmış çok yönlü bir sanatçı ve tasarımcıdır. İngiltere de Royal College of Art'dan mezun olan sanatçı, kendi atölyesindeki çalışmalarının yanı sıra sanat eğitimi veren okul ve üniversitelerde kısa aralıklı dersler vermekte ve gerek Ingiltere ve gerekse de dünyanın çeşitli ülkelerinde çalışma gruplarında faaliyetlerde bulunmaktadır.

31937 yılında Erzurum'un Oltu ilçesinin İnci köyünde dünyaya geldi. 1956 yılından emekli olduğu 1987 yılına kadar çeşitli yerlerde müezzinlik ve imamlık yaptı. 1964'den başlayarak önce Hattat Halim Özyazıcidan sonra Hattat Hamid Aytaçtan hat dersleri aldı. Çok sayıda ödüllü çalışmalarının yanı sıra, Cumhurbaşkanlığı Kültür ve Sanat Büyük Ödülü Sahibidir.

41974 yılında Suriye'de doğdu. Hattat Adnan eş-Şeyh Osman'dan hat dersleri aldı. Uluslararası etkinliklerde juri uyelikleri ve çok sayıda ödüle sahip olup halen Şarja Hat ve Tezhip Merkezi'nin hat sanatı hocası ve sorumlusudur.

51977 yılında Kahire Arapça Hat Geliştirme Okulu ve Mısır düzeyinde Arapça hat sanatında birinci sırada gelen Mısır Arap Cumhuriyeti düzeyinde Seçkin Öğrencilerin okuduğu Al Awael'den diploma aldı. Ünlü hattat Syed İbrahim ile Mısır'da çalıştı. Emirates Plastik Sanatlar Derneği üyesi olup, Sharjah, Abu Dabi (Kültür Vakfı) ve Al Ain ile ilgili tüm sergilere katıldı. Uluslar arası çok sayıda ödüle sahiptir.

\section{Kaynakça}

\section{Internet kaynakları}

(Mimarizm, 2008)

http://www.mimarizm.com/KentinTozu/Makale. aspx?id=374\&sid $=387$

(Syriart, 2012)

http://www.syriaart.com/new/index.

php?page=viewArtist\&id=19

(en.wikipedia, 2012)

http://en.wikipedia.org/wiki/Sheikh_Zayed_Mosqu

(08.05.2012)

(eogrenme.anadolu, 2012)

http://eogrenme.anadolu.edu.tr/ekitap/ilh1005.pdf

(szgmc.ae, 2012)

http://www.szgmc.ae/en/ 
(abudhabi.ae, 2012)

http://www.abudhabi.ae/egovPoolPortal_WAR/ appmanager/ADeGP/Citizen?_nfpb=true\&_pageLabel=p_ citizen_homepage_hidenav\&lang=en\&did=104596

(Makrana, 2012) http://www.makranamarble.org/category/uncategorized/ (bigprojectme, 2013) http://www.bigprojectme.com/interviews/the-jewel-inabu-dhabis-crown/

(Kevindean,2012) http://www.kevindean.co.uk/workshops.html

(gulfnews, 2013)

http://gulfnews.com/business/features/layingthe-groundwork-for-artistic-union-1.522446/shaikh-zayedmosque-1.522584

(iznik.com, 2012)

http://www.iznik.com/tr/projeler/camiler/-/sheikhzayed-cami

(kimkimdir, 2013)

http:/ / www.kimkimdir.gen.tr/kimkimdir.php?id=6021

(tccb.gov, 2012)

http://www.tccb.gov.tr/haberler/170/81940/

cumhurbaskani-gul-seyh-zayed-camiini-ziyaret-etti.html

(fanar.gov.qa, 2011)

http://www.fanar.gov.qa/ArabicCalligraphy.aspx

(dubaifaqs, 2013)

http://www.dubaifaqs.com/sheikh-zayed-mosque.php

(albarakaturk, 2008)

http://www.albarakaturk.com.tr/images/

albarakayasam/2008_tezhibli_hatkatalogu20pdf

(mandiarts, 2011)

http://www.mandiarts.com/PROFILE.HTM

(payvand, 2007)

http://www.payvand.com/news/07/aug/1001.html

(speirsandmajor, 2012)

http://www.speirsandmajor.com/blog/article/entry_ speirs_major_win_iald_radiance_award_for_third_ consecutive year/

(halcrow, 2012)

http://www.halcrow.com/Our-projects/Project-

details/Grand-Mosque-Abu-Dhabi/

(peri, 2012)

http://www.peri.de/ww/en/projects.cfm/fuseaction/

diashow/reference_ID/117/currentimage

\section{Görsel Kaynaklar}

Fotoğraf 1. Şeyh Zayed bin Sultan El Nayan türbesi (yesügey, 2009)

Fotoğraf 2. Caminin yeri (abudhabi.ae 1, 2012)

http://www.abudhabi.ae/egovPoolPortal_WAR/

appmanager/ADeGP/Citizen?_nfpb=true\&_pageLabel=P14

$00288491284970418871 \&$ lang $=e n$

Fotoğraf 3. Havadan görünüş (randomphotography, 2012) http://www.randomphotography.in/2012/02/sheikhzayed-grand-mosque-abu-dhabi-uae/

Fotoğraf 4. Ana yapı plan (archpresspk, 2012) http://archpresspk.com/Aplusi19_Mosque.htm (cephe ve plan çizimleri)

Fotoğraf 5. İç Avlu (Kevindean,2012) http://www.kevindean.co.uk/murals.html

Fotoğraf 6. Çiçek Motifli Mermer Kaplama (thishandcraftedlife, 2012) http://thishandcraftedlife.wordpress.com/category/

decorative-painting/painted-stone/

Fotoğraf 7. Revak ve havuz (wirednewyork, 2012) http://wirednewyork.com/forum/showthread. php?p=256363 (12.04.2012)

Fotoğraf 8. Revaklı geçit (nicolholden designes, 2012) http://www.nicolaholdendesigns.co.uk/blog/category/ architecture/the-sheikh-zayed-grand-mosque/

Fotoğraf 9. Ana Giriş (thishandcraftedlife,2012) http://thishandcraftedlife.wordpress.com/category/ decorative-painting/painted-stone/

Fotoğraf 10. Ana Giriş ve Avizeli Salon

Fotoğraf 11. Duvar Süslemeleri (dubaiinmyeyes, 2012) http://dubaiinmyeyes.blogspot.com/2012/10/sheikhzayed-grand-mosque-abu-dhabi-

Fotoğraf 12. (Hewy, 2012) I

http://www.flickr.com/photos/hewy/6112195178/in/ photostream/

Fotoğraf 13. (mattwagers, 2008) http://www.flickr.com/photos/mattwagers/3118530275/

Fotoğraf 14. (@N04, 2011) http://www.flickr.com/photos/51014357@ N04/5552385755/

Fotoğraf 15. (jenny, 2008) http://www.flickr.com/photos/ infinitewhite/4808163629/in/photostream/

Fotoğraf 16. (iznik, 2012) http://www.iznik.com/tr/projeler/camiler/-/sheikhzayed-cami

Fotoğraf 17.-18. Mihrap ve Minber (yesügey, 2009)

Fotoğraf 19. Dörderli taşıyıcı kolon (yesügey, 2009) 
Fotoğraf 20-21. İç mekân (yesügey, 2009)

Fotograf 22. Kıble Duvarı (deviantart, 2013)

http://celestial22.deviantart.com/art/Sheikh-Zayed-

Grand-Mosque-II-320263794

Fotoğraf 23-24. Duvar Yazı (amatraveller, 2011)

http://www.amatraveller.com/2011/11/13/my-visit-to-

sheikh-zayed-mosque-abu-dhabi/

Fotoğraf 25. Halı (yesügey, 2009)

Fotoğraf 26. Vitraylar (dubaiinmyeyes, 2012)

Fotoğraf 27. Büyük avize (yesügey, 2009)

Fotoğraf 28. Dış mekân aydınlatma kuleleri (wirednewyork, 2012)

Fotoğraf 29. Aydınlatma (wirednewyork, 2012)

http://www.nicolaholdendesigns.co.uk/blog/category/

architecture/the-sheikh-zayed-grand-mosque/ 